\title{
A IMPORTÂNCIA E AS VANTAGENS DO POLIHIDROXIBUTIRATO (PLÁSTICO BIODEGRADÁVEL)
}

\author{
B. C. Coutinho' ${ }^{\text {; }}$ G. B. Miranda ${ }^{1}$; G. R. Sampaio ${ }^{1}$; L. B. S. De Souza ${ }^{2}$; W. J. Santana ${ }^{2}$; \\ H. D. M. Coutinho ${ }^{2,3}$
}

1 Discente - Faculdade de Medicina de Juazeiro do Norte - FMJ

2 Docente - Faculdade de Medicina de Juazeiro do Norte - FMJ

3 Docente - Universidade Regional do Cariri - URCA

hdouglas@zipmail.com.br / h-douglas@bol.com.br

Recebido em agosto/2004 e Aceito em dezembro/2004

\section{RESUMO}

Do início do século passado aos dias atuais o uso dos polímeros tem se tornado cada vez mais freqüente na sociedade. Existe uma incrível quantidade de artigos que utilizam polímeros como matéria-prima para suas diferentes elaborações. A busca inicial por polímeros sintéticos esteve baseada em sua relativa inércia e resistência a biodegradação. Devido a essas características, a enorme quantidade de lixo produzido nas cidades tornouse um sério problema, estimulando a substituição desse material de difícil degradação por um polímero natural biodegradável, o Polihidroxibutirato (PHB), alvo das pesquisas atuais. A importância do PHB está no fato de poder ser usado na fabricação de diversos produtos. O tempo médio de degradação desses bioplásticos é de 6 a 12 meses contra 40 a 50 anos ou até 200 anos no caso dos polímeros sintéticos. Apesar da vantagem no critério ambiental, os plásticos biológicos são mais caros e, por serem menos flexíveis, têm aplicações mais limitadas que os sintéticos.

Palavras-chave: Polihidroxibutirato; PHB; Biodegradação; Indústria

\section{IMPORTANCE AND ADVANTAGES OF POLYHYDROXYBUTYRATE (BIODEGRADABLE PLASTIC)}

\begin{abstract}
From the beginning of the last century to the current days the use of polymers has become more frequent in the society. Have a incredible amount of devices produced by the man and that use polymers as raw material to its different elaborations. The initial search for synthetic polymers was based on its relative inertia and resistance biodegradation. Due to this durability, the enormous amount of garbage produced in the social communities became a serious problem today. As a way to attenuate this reality, the substitution of this difficult degradation material for a biodegradable natural polymer, Polyhydroxybutyrate (PHB), is being white of research. The importance of the PHB is shown in the using in several products. The order of magnitude of the degradation of these bioplastics is of 6 to 12 months, against 40 the 50 years or up to 200 years in the case of synthetic polymers. Despite the advantage for the environment, the biological plastics are more expensive and, for being less flexible, it has more limited applications than the synthetic ones.
\end{abstract}

Key-words: Polyhydroxybutyrate; PHB; Biodegradation; Industry 


\section{A IMPORTÂNCIA E AS VANTAGENS POLIHIDROXIBUTIRATO (PLÁSTICO BIODEGRADÁVEL)}

\section{INTRODUÇÃO}

Do início do século passado aos dias atuais, o uso dos polímeros tem se tornado cada vez mais freqüente na sociedade. Basta um olhar ao redor para se perceber a incrível quantidade de artefatos produzidos pelo homem e que se utilizam polímeros como matériaprima para suas diferentes elaborações. Das garrafas de refrigerantes, passando pelas hastes de cotonetes, sacos de supermercados, tubos de PVC, recipientes de poliestireno expandido, revestimentos de panelas e de latas de conserva, mamadeiras, tintas para paredes, próteses, escovas de dente, pára-choques de veículos, tapetes, cobertores, pneus ou suportes para componentes eletrônicos, os polímeros estão presentes em quase a totalidade dos utensílios de uso cotidiano (Rosa et al, 2002).

A busca inicial por polímeros sintéticos esteve baseada em sua relativa inércia e resistência a biodegradação, ao contrário dos polímeros naturais como amido, celulose e proteínas. Os primeiros estudos relativos a biodegradação foram realizados visando retardar e prevenir o ataque por fungos, bactérias e outros organismos vivos a esses materiais. Em particular, os polímeros formados por hidrocarbonetos são resistentes ao ataque químico e biológico, de tal forma que isso lhes assegura longevidade e outras propriedades que se mantém por longo tempo (Rosa et al, 2001).

Dada à principal propriedade da grande maioria dos polímeros - a durabilidade um sério problema acompanha o homem contemporâneo: a enorme quantidade de lixo produzido nas comunidades sociais, principalmente nos grandes centros urbanos. Esse lixo, constituído em grande parte por produtos industrializados produzidos com polímeros sintéticos, pode permanecer por mais de uma centena de anos para se decompor, resultando em problemas ambientais que podem ser desastrosos para a humanidade ( Rosa et al, 2002).

O Polihidroxibutirato (PHB) é um composto de uma classe dos polímeros termoplástico chamados "polihidroxialcanoatos" que servem a muitas bactérias como uma maneira de armazenar dentro da célula, materiais que podem servir de reserva para obtenção de carbono e como fonte de energia para o caso de ausência de um dos dois. As plantas modificadas geneticamente para produção de PHB como a batata (Solanum tuberosum) e tabaco (Nicotiana tabacum), podem fornecer outros meios de produzir este polímero. O PHB pode ser usado na fabricação de embalagens para produtos de limpeza, higiene, cosméticos e produtos farmacêuticos. Também serve para produzir sacos e vasilhames para fertilizantes e defensivos agrícolas, vasos para mudas e produtos injetáveis. Além disso, por ser biocompatível e facilmente absorvido pelo organismo humano, pode ser empregado na área médico-farmacêutica, prestando-se à fabricação de fios de sutura, próteses ósseas e cápsulas que liberam gradualmente medicamentos na corrente sanguínea (Bohmert et al, 2002).

O objetivo desse trabalho foi trazer de volta a discussão deste tema de tão grande interesse do ponto de vista ambiental e econômico através de uma revisão bibliográfica utilizando as mais recentes referências para demonstrar em que nível se encontram as pesquisas sobre PHB e informá-las a sociedade. 


\section{PESQUISAS SOBRE PHB NO BRASIL.}

No Brasil, em meados da década de 90, deu-se início ao desenvolvimento de tecnologia para a produção de plásticos biodegradáveis e biocompatíveis empregando matéria-prima renovável pela agricultura, em especial derivados da cana-de-açúcar. Após um levantamento de oportunidades, selecionou-se um grupo de polímeros da família dos polihidroxialcanoatos (PHA) que podem ser produzidos por bactérias em biorreatores a partir de carboidratos. Tais polímeros, em condições apropriadas de cultivo bacteriano, são acumulados na forma de grânulos intracelulares, os quais podem ser separados e removidos após a destruição da célula para obtenção dos grânulos intracelulares de PHB, gerando uma resina com propriedades semelhantes às dos plásticos de origem petroquímica, com a vantagem de poderem ser biodegradados no ambiente por microrganismos nele existentes em curto espaço de tempo após o descarte, onde o tempo para degradar vai depender do que foi adicionado à resina considerada biodegradável. A ordem de grandeza da degradação desses bioplásticos é de meses ( 6 a 12 meses) contra 40 a 50 anos ou até 200 anos no caso dos polímeros sintéticos. Descobertos há cerca de dez anos, os plásticos biodegradáveis ainda têm uma participação mínima no mercado internacional (cerca de 1\%), dominado pelos de origem petroquímica. Apesar da vantagem no critério ambiental, os plásticos biológicos são, em média, $40 \%$ mais caros e, por serem menos flexíveis, têm aplicações mais limitadas que os sintéticos (Bohmert et al, 2002).

\section{INDÚSTRIA}

O mercado mundial de plástico é da ordem de 200 milhões de toneladas por ano. Segundo estimativas de vários especialistas, a fatia desse mercado que deve ser ocupada pelos bioplásticos gira em torno de $1 \%$ a $2 \%$ nos próximos dez anos. E a PHB quer participar dessa fatia. $\mathrm{Na}$ indústria, pesquisas com o $\mathrm{PHB}$ estão centradas em produtos de rápido descarte, como barbeadores, embalagens de cosméticos, copos e talheres plásticos. Muitas empresas reconhecem que ter um produto feito com plástico biodegradável é um diferencial importante (Rosa et al, 2002).

Um dos objetivo da indústria é empregar a Burkholderia saccharina na produção industrial de PHB. A vantagem seria que ela pode ser integrada totalmente à linha de produção da usina de açúcar. A energia para cultivo da bactéria vem da queima de bagaço de cana. O alimento é o próprio açúcar e o solvente usado para retirar o polímero das bactérias é a glutationa. Até os efluentes da linha de produção têm aplicação dentro da cadeia produtiva: são usados para fertirrigação. Para cada 3 quilos de açúcar utilizado para alimentar as bactérias é possível obter 1 quilo de plástico (Rosa et al, 2002).

Vários estudos foram realizados com respeito a aplicação do PHB na indústria: Uma aplicação do PHB na indústria é modificar propriedades da fibra quando sintetizada em algodão. A presença de granules de PHB em fibras transgênicas resultaram em mudanças das propriedades térmicas (aporte de calor total, capacidade relativa de transmissão de calor, condutividade térmica e calor específico), tornando-se um procedimento importante na produção de novas gerações de fibras para a indústria têxtil. (Jonh \& Keller, 1996). 
Evidências para a produção de PHB em plantas foi obtida modificando dois genes da bactéria Alcaligenes eutrophus de modo que os polipeptídeos fossem produzidos no citoplasma dessas plantas. (Somerville et al, 2001).

O PHB foi produzido a partir do cultivo de diversas bactérias gram-negativa, incluindo Ralstonia eutropha, Alcaligenes latus e Escherichia coli recombinante (Lee et al, 1999). Três genes da Ralstonia eutropha (anteriormente Alcaligenes eutrophus) que codifica as enzimas para a síntese PHB (phbA, phbB, phbC) e um copolímero do PHB, o polihidroxivalerato, projetado para a escolha do plástico foram introduzidos na alfafa pela transformação mediada por Agrobacterium. As análises do DNA e do RNA de plantas transgênica indicaram que o material genético conseguiu ser integrado no novo genoma e conseguiu se expressar (Saruul et al, 2002 ).

Estudos estão sendo realizados na biossíntese de PHB através da identificação da Methylobacterium extorquense e mutação de gap11, de gap20, e de phaR. (Korotkova et al, 2002 ). Outros estudos mostram que o Polihidroxibutirato (PHB) é o PHA melhor caracterizado. PHB foi produzido em Arabidopsis thaliana e no algodão de A. eutrophus expressando biosíntese enzimática. Síntese de alto nível de PHB nas plantas abriu a possibilidade de usar colheitas agrícolas como sistemas apropriados para a produção de PHAs em grande escala e de custo baixo (Mittendorf et al, 1998).

Os genes envolvidos na síntese PHB, do DNA ao plástico, tem sido analisadas extensivamente por técnicas bioquímicas e forneceram indícios sobre a regulação do processo (Madison \& Huisman, 1999). Foi investigada a participação dos genes glnB, glnZ, e glnD na regulação da biosíntese de Poly-3-Hidroxibutirato. Foi observado que os mutantes desses genes produzem quantidades substancialmente mais elevadas de PHB do que os de tipos selvagem (Sun et al, 2002).

Uma nova possibilidade é o papel da Fasina (gene PhaP) de Ralstonia eutropha em promover a síntese de PHB. Fasinas são proteínas importantes na síntese do polihidroxialcanoato e na formação do granulo (York et al, 2001a,b). A acumulação das fasinas foi proposta ser dependente da produção de PHA, um modelo que foi testado agora para a fasina PhaP do Ralstonia eutropha (Lee et al, 1999).

Atualmente, os Polihidroxialcanoatos (PHAs) estão sendo produzidos por diversas bactérias que os acumulam como grânulos intracelulares. No ramo da genética, já houve estudos de clonagem de um gene intracelular da Ralstonia eutropha H16 e caracterização do produto desse gene (Saegusa et al, 2001), além da biossíntese do Polihidroxibutirato no Caulobacter crescentus (Qi \& Rehm, 2001).

\section{BIODEGRADAÇÃo}

Uns dos maiores desafios ambientais da atualidade é o esgotamento dos recursos não renováveis e o equacionamento da questão do lixo urbano, fatores diretamente ligados ao setor de embalagens, apontado como um dos principais agentes multiplicadores desses resíduos. Em 2000, o Brasil produziu aproximadamente 23 mil toneladas de lixo/dia, sendo em média $20 \%$ desse volume correspondente aos plásticos. Desta forma, torna-se essencial o desenvolvimento de alternativas que possam compatibilizar a praticidade das embalagens e o desenvolvimento sustentável, permitindo o consumo e a conveniência, sem 
comprometer os recursos do planeta. Trata-se do PHB, um polímero totalmente biodegradável, extraído a partir da sintetização do açúcar da cana por bactérias da espécie Ralstonia eutropha. Estes microrganismos alimentam-se do açúcar e os transformam em grânulos intracelulares que são, na verdade, poliésteres. É um material desenvolvido pelo IPT/Coopersucar, que em aterros sanitários chega a atingir $50 \%$ de degradação em 280 dias, transformando-se em gás carbônico e água, sem liberação de resíduos tóxicos (Rosa et al, 2002).

\section{CONCLUSÃO}

Apesar da vantagem no critério ambiental, os plásticos biológicos são mais caros e, por serem menos flexíveis, têm aplicações mais limitadas que os sintéticos. Além disso, eles não contribuem para o aumento do $\mathrm{CO}_{2}$ na atmosfera, visto que ao serem degradados, esse carbono passa a fazer parte da matéria orgânica do ambiente As características físicas e mecânicas do plástico biodegradável são semelhantes às de alguns polímeros sintéticos, que utilizam o petróleo como matéria-prima, mas oferecem o benefício de se decompor muito mais rapidamente depois de descartados.

O PHB vai atender aos requisitos de uma área específica de mercado, pois muitas empresas reconhecem que ter um produto feito com plástico biodegradável é um diferencial importante. $\mathrm{O}$ que é preciso agora é atender o que o mercado requer desse polímero, lembrando que por mais que se avance em tecnologia não haverá um custo mais baixo a não ser que seja modificada a forma de fabricação do PHB. Da mesma forma que levou-se 60 anos para multiplicar as variedades de uso do polietileno, desde a sua descoberta em 1940, o bioplástico vai entrar para uma etapa de novas opções.

\section{REFERÊNCIAS BIBLIOGRÁFICAS}

BOHMERT, K.; BALBO, I.; STEINBÜCHEL, A.; TISCHENDORF, G.; WILLMITZER, L. 2002. Constitutive Expression of the -Ketothiolase Gene in Transgenic Plants. A Major Obstacle for Obtaining Polyhydroxybutyrate-Producing Plants. Plant Physiol. 128:1282-1290.

JOHN, M.E. \& KELLER, G. 1996. Metabolic pathway engineering in cotton: Biosynthesis of polyhydroxybutyrate in fiber cells. Proc. Natl. Acad. Sci. USA. 93:12768-12773.

KOROTKOVA, N.; CHISTOSERDOVA, L.; LIDSTROM, M.E. 2002. Poly-ßHydroxybutyrate Biosynthesis in the Facultative Methylotroph Methylobacterium extorquens AM1: Identification and Mutation of gap11, gap20, and phaR. J Bacteriol. 184(22):6174-6181.

LEE, S.Y.; CHOI, J.; HAN, K.; SONG, J.Y. 1999. Removal of Endotoxin during Purification of Poly(3-Hydroxybutyrate) from Gram-Negative Bacteria. Appl Environ Microbiol.65(6):2762-2764 
MADISON, L.L. \& HUISMAN, G.W. 1999. Metabolic Engineering of Poly(3-

Hydroxyalkanoates): From DNA to Plastic. Microbiol Mol Biol Reviews. 63(1):21-53.

MITTENDORF' V.;ROBERTSON, E.J.; LEECH, R.M.; KRÜGER, N.; STEINBÜCHEL, A.; POIRIER, Y. 1998.Synthesis of medium-chain-length polyhydroxyalkanoates in Arabidopsis thaliana using intermediates of peroxisomal fatty acid -oxidation. 95(23):13397-13402.

QI, Q. \& REHM, B.H.A. 2001. Polyhydroxybutyrate biosynthesis in Caulobacter crescentus: molecular characterization of the polyhydroxybutyrate synthase. Microbiology. 147:3353-3358.

ROSA, D.S.; FRANCO, B.L.M.; CALIL, M.R. 2001. Biodegradabilidade e Propriedades Mecânicas de Novas Misturas Poliméricas. Polímeros, 11(2): 82-88.

ROSA, D.S.; HANG-CHUI, Q. S.; PANTANO FILHO, R.; AGNELLI, J.A.M. 2002. Avaliação da Biodegradação de Polị- -(Hidroxibutirato), Poli- -(Hidroxibutirato-covalerato) e Polị- $\xi$-(caprolactona) em Solo Compostado. Polímeros. 12(4): 311-317.

SAEGUSA, H.; SHIRAKI, M.; KANAI, C.; SAITO, T. 2001. Cloning of an Intracellular Poly[D(-)-3-Hydroxybutyrate] Depolymerase Gene from Ralstonia eutropha H16 and Characterization of the Gene Product. J Bacteriol. 183(1):94-100.

SARUUL, P.; SRIENC, F.; SOMERS, D.A.; SAMAC, D.A. 2002. Production of a Biodegradable Plastic Polymer, Poly-ß-Hydroxybutyrate, in Transgenic Alfalfa. Crop Science 42:919-927.

SOMERVILLE, C.R. \& BONETTA, D. 2001. Plants as Factories for Technical Materials. Plant Physiol. 125:168-171

SUN, J.; DOMMELEN, A.V.; IMPE, J.V.; VANDERLEYDEN, J. 2002. Involvement of glnB, glnZ, and glnD Genes in the Regulation of Poly-3-Hydroxybutyrate Biosynthesis by Ammonia in Azospirillum brasilense Sp7. Appl Environ Microbiol.68:2985-988

YORK, G.M.; JUNKER,B.H.; STUBBE, J.; SINSKEY, A.J. 2001a. Accumulation of the PhaP Phasin of Ralstonia eutropha Is Dependent on Production of Polyhydroxybutyrate in Cells. J Bacteriol., 183(14):4217-4226.

YORK, G.M.; STUBBE, J.; SINSKEY, A.J. 2001b.New Insight into the Role of the PhaP Phasin of Ralstonia eutropha in Promoting Synthesis of Polyhydroxybutyrate. J Bacteriol. 183(7):2394-2397. 